\title{
The role of spiritual intelligence in citizenship behaviours amongst Muslim staff in Malaysia
}

\begin{tabular}{|c|c|}
\hline $\begin{array}{l}\text { Authors: } \\
\text { Dini T. Alaman } \\
\text { Israr Ahmad² } \\
\text { Halim D. Putra } \\
\text { Nik A. Hashim }\end{array}$ & $\mathrm{da}^{1}$ \\
\hline $\begin{array}{l}\text { Affiliations: } \\
{ }^{1} \text { Faculty of Eco } \\
\text { University, Jay } \\
\text { Indonesia }\end{array}$ & $\begin{array}{l}\text { nomics, Garut } \\
\text { a Barat, }\end{array}$ \\
\hline $\begin{array}{l}{ }^{2} \text { School of Bus } \\
\text { Management, } \\
\text { Utara Malaysi } \\
\text { Malaysia }\end{array}$ & $\begin{array}{l}\text { ness } \\
\text { Universiti of } \\
\text {, Kedah, }\end{array}$ \\
\hline $\begin{array}{l}{ }^{3} \text { Faculty of Eco } \\
\text { Politeknik Neg } \\
\text { Riau, Indonesi }\end{array}$ & $\begin{array}{l}\text { nomics, } \\
\text { eri Bengkalis, }\end{array}$ \\
\hline $\begin{array}{l}{ }^{4} \text { Faculty of Ho } \\
\text { Tourism and } \\
\text { Universiti Mal } \\
\text { Malaysia }\end{array}$ & $\begin{array}{l}\text { pitality, } \\
\text { ellness, } \\
\text { ysia Kelantan, }\end{array}$ \\
\hline $\begin{array}{l}{ }^{5} \text { Dean's Office, } \\
\text { Theology and } \\
\text { University of P } \\
\text { Pretoria, Sout }\end{array}$ & $\begin{array}{l}\text { Faculty of } \\
\text { Religion, } \\
\text { retoria, } \\
\text { Africa }\end{array}$ \\
\hline $\begin{array}{l}\text { Correspondin } \\
\text { Israr Ahmad, } \\
\text { chaudhryisrar }\end{array}$ & $\begin{array}{l}\text { author: } \\
\text { Dgmail.com }\end{array}$ \\
\hline $\begin{array}{l}\text { Dates: } \\
\text { Received: } 03 \\
\text { Accepted: } 02 \\
\text { Published: } 16\end{array}$ & $\begin{array}{l}\text { lar. } 2021 \\
\text { uly } 2021 \\
\text { Vov. } 2021\end{array}$ \\
\hline $\begin{array}{l}\text { How to cite th } \\
\text { Alamanda, D.T } \\
\text { Putra, H.D. \& } \\
\text { 2021, 'The rol } \\
\text { intelligence in } \\
\text { behaviours am } \\
\text { Muslim staff ir } \\
\text { HTS Teologies } \\
\text { Theological St } \\
\text { a6586. https:/ } \\
\text { 10.4102/hts.v }\end{array}$ & $\begin{array}{l}\text { is article: } \\
\text {, Ahmad, I., } \\
\text { lashim, N.A., } \\
\text { of spiritual } \\
\text { citizenship } \\
\text { ongst } \\
\text { Malaysia', } \\
\text { Studies/ } \\
\text { dies } 77(1) \text {, } \\
\text { 'doi.org/ } \\
\text { 7i1.6586 }\end{array}$ \\
\hline Read online: & \\
\hline 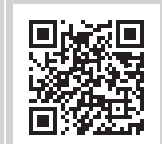 & $\begin{array}{l}\text { Scan this QR } \\
\text { code with your } \\
\text { smart phone or } \\
\text { mobile device } \\
\text { to read online. }\end{array}$ \\
\hline
\end{tabular}

Religion is so rich, comprehensive and complex that its different aspects exhibit differently in different perspectives and attitudes. Good employees express their opinions and beliefs honestly and participate in the organisational activities. In other words, they take actions that are not necessary but are useful for colleagues and organisations. These behaviours, called extra-role or organisational citizenship behaviours (OCB), refer to activities that are inherently spontaneous and conscious and are not directly and explicitly predicted by the organisation's formal reward system, but generally enhance the organisation's efficiency. The importance of such behaviours in religious and spiritual environments increases. Hence, this study aimed to determine the role of spiritual intelligence in exhibiting citizenship behaviours in the organisation. Therefore, 5000 employees of 40 manufacturing and services companies working in the education, finance, insurance and food sectors were selected by simple random sampling method as the statistical population of the study. Then, standard questionnaires were distributed amongst the participants, necessary data were collected and Statistical Package for the Social Sciences (SPSS) was used to analyse data. The results indicated a positive and significant relationship between spiritual intelligence and citizenship behaviours in organisations. Finally, the Structural Equation Model (SEM) results in linear structural relations (LISREL) showed that spiritual intelligence affects the citizenship behaviours $(p=0.68)$.

Contribution: This article therefore contributes to the spirituality and spiritual intelligence of employees in the organisation as an aspect of religion.

Keywords: religion; spirituality; intelligence; spiritual intelligence; citizenship behaviour; Malaysia.

\section{Introduction}

One of the main characteristics of progress and a symbol of healthy movement in human evolution is the observance of social ethics in society and in manufacturing and service organisations in Islamic society. This role is more prominent and effective in the Islamic society because of the special position of organisations in meeting the needs of citizens (Khaninzadeh 2016). In this century, societies are facing many social, cultural and economic problems; most experts believe that solving many of the existing problems requires citizens who not only have to possess wise abilities but also equally have significant social skills (Cropanzano, Rupp \& Byrne 2003). Intelligence is one of the most influential concepts of mental processes whose effects are observed differently in various organisms; the more evolved beings are, the more advanced they are in intelligence and the more complex they are. The scope of spirituality is developing today in a variety of majors such as Medicine, Psychology, Anthropology and Cognitive sciences (Amrai et al. 2011). Intelligence has long been considered as one of the causes of success in life, but the important issue is that intelligence quotient (IQ) does not determine a person's long-term success. In other words, it is not always the case that anyone with higher intelligence is more successful. In some cases, there are intelligent people who are not successful in their own lives, and conversely, there are people with less IQ who achieve a lot of success (Bigdeloo \& Bozorgi 2016). The last years of the 20th century have seen evidence of Psychology, Neurology, Anthropology and Cognitive science so that there is a type of intelligence affecting the success of individuals (Du, Mazdarani \& Ghasemian 2013). This type of intelligence is referred to as spiritual quotient (SQ). Recent advances in organisational behaviour show that brain function has undoubtedly been associated with individuals' spiritual experiences. In other words, the researchers found areas in the brain with activities responsible for spirituality called the God spot, because the stimulation of these areas directs the individual towards religion, religiosity, God, spirituality and similar

Copyright: @ 2021. The Authors. Licensee: AOSIS. This work is licensed under the Creative Commons Attribution License.

Note: Special Collection: Faith Seeking Understanding, sub-edited by Seyed Mehdi Mousavi (Payame Noor University, Tehran, Iran) and the Dean's Office of the Faculty of Theology and Religion of the University of Pretoria. 
topics. The SQ is one of the psychological concepts with a strong connection with the value system and its strengthening. The emergence of SQ structure in general can be considered as the application of spiritual values and resources in practical contexts and situations. Individuals use SQ when they tend to use spiritual capacities and values to make important decisions and thoughts on fundamental issues or to try to solve problems in their lives (Emmons 2000b). A human being acts with flexible SQ, without prejudice, circumscription, restriction or prejudice, because of the ability to perceive justice at the same time. It can be said that spiritual human beings have a degree of moral and emotional development, as well as moral behaviour (Gieseke 2014). Intelligence is one of the fundamental concepts in psychology that has been extensively studied and researched. Despite these efforts in terms of complexity and multiplicity, as well as the various factors involved in intelligence, experts have not yet reached a general agreement on the dimensions and even the precise definition of intelligence (Griffiths et al. 2008). Some attribute this to the different meanings of intelligence in specialised fields and different systems of psychology and others emphasise that an item considered in one culture of intelligence may be a non-intelligence phenomenon in another culture (Adams \& Hyde 2008). In Western culture, intelligence is more cognitive and includes information processing (Tischler, Biberman \& McKeage 2002), whilst in Eastern culture, intelligence has a combined approach that covers various components of human performance and experience, including cognition, intuition and emotion, within an integrated relationship (King \& DeCicco 2009).

Emmons (2000a) mentioned five points about SQ, thus that high SQ is a gift for a person with the following characteristics: (1) the capacity to use spiritual resources in problem solving, (2) the ability to raise awareness, (3) the ability to relate daily activities to sacred concepts, (4) the ability to perceive material and physical issues and (5) the ability to train a benevolent individual. In addition, Levin (2000) claimed that the SQ will become apparent when individuals integrate their daily lives with spirituality. According to Zohar and Marshall (2000), the SQ is the intelligence in the face of the question of meaning and value, which puts our characteristics, traits and lifestyles in a richer and broader environment. Zohar and Marshall (2000) knew the SQ as a more complete intelligence than other ones, especially emotional intelligence, because the SQ is based on human socialisation and spirituality, in addition to emotions and excitement. Thus, the SQ acts as a platform for the efficient functioning of the human brain and emotions (Nasel 2004), meaning that a person with a high SQ has the capacity to control emotions and feelings and the ability to make decisions (Saidy et al. 2009). They reported the SQ as a guide in life capable of distinguishing good from bad. It has also been argued that the SQ has the ability to create meaning by relating ideas, events and people (Fry 2003). In addition, the SQ is defined as the ability to create meaning by linking people's life experiences and spirit (Yang 2006). According to Wolman (2001), the SQ is the human capacity to ask questions about the meaning of life and to experience the connection between each of us and the world in which we live. According to Vaughan (2002), the SQ deals with the inner life of mind and soul and their association with being in the world. The SQ involves the capacity for deep understanding of questions about the universe. The SQ appears as a consciousness in the life, body, mind and soul of a person. In addition, the SQ can be promoted by exercises, allowing people to recognise facts and fantasies.

Organisational citizenship behaviour (OCB), on the other hand, is a new topic in industrial and organisational psychology, whose importance continues to grow (Koys 2001). Human behaviour is one of the fields of study constantly considered by social scientists. Human behaviour has different dimensions that are studied by sciences such as Psychology, Sociology and Management in different environments (Organ 1988). Measuring the type of behaviour, guiding and predicting behaviour are some of the objectives of studying behaviour that can be achieved by assessing variables such as motivation, values and attitudes, perception, personality and feeling. Human behaviour is regulated in the form of roles in different environments (Ozsahin \& Sudak 2015). People perform tasks in the role they are in, and are expected to exhibit certain behaviours. For example, a person as a citizen is obliged to refrain from violating the rights of others in his role. Laws sometimes draw red lines for citizens to control and direct these behaviours in communities (Podsakoff \& MacKenzie 1994). In addition to the behaviours expected of each person in the form of roles, there are behaviours rooted in principles such as culture, history and religion of a society. Voluntary behaviours performed in societies according to values, including respect for the elderly in society, are manifested as meta-roles. These behaviours within organisations are called organisational citizenship behaviour (Chan \& Lai 2017). Citizenship behaviours are meta-role, voluntary and innovative behaviours by employees in the organisation. Although these behaviours are out of the official duties of employees and do not bring rewards for employees by the organisation (Bateman \& Organ 1983), the reason for the study is their effects on improving the effectiveness and efficiency of organisations. For example, behaviours such as helping train newcomers to the organisation, using breaks to complete work, making suggestions for the improvement of working procedure and acting on projects at home, are all considered OCBs (Bolino et al. 2015).

Taking into account the importance of the study, there is little attention given to research on the relationship between spiritual intelligence and citizenship behaviours amongst Muslim staff, especially in Malaysia. Therefore, the present study examines the role of spiritual intelligence in citizenship behaviours amongst Muslim staff in Malaysia in 2020.

\section{Spiritual intelligence in Islam}

It should be observed that today there is a need to raise the issue of SQ in different ways. The SQ empowers people to 
find solutions to problems with life. Introduction of concepts such as ethics, truth, metacognitive belief, belief in higher power, honesty, conscience, magnanimity, forgiveness, trust, kindness, meaning at work, solidarity with colleagues, altruism in the workplace and increasing new research with new concepts, all indicate the emergence of a new paradigm. 'Spiritual intelligence', as its title suggests, combines the concepts of 'spirituality' and 'intelligence' into one single new construct (Ghobani Bonab et al. 2005). As spirituality reaches excellence through the search and experience of sacred elements, the SQ requires abilities that use spiritual subjects to adapt and act effectively and produce valuable products and outcomes and requires a framework for identifying and organising skills and capabilities; in a way that spirituality increases a person's adaptability. In the original culture of Islam, the SQ has implicitly received much attention. The SQ or the power of reason and thought in mankind is a divine gift and a merciful light that is considered the inner prophet of human being and naturally tends to charity and perfection and seeks justice and benevolence. This intelligence and ability is the criterion of duty, reward and punishment, which causes the distinction between right and wrong, good and evil and the way and wayless, and thereby distinguishing ugly from beautiful and perfection and lowliness (Ghobani Bonab et al. 2005).

Factors affecting SQ in Islamic texts include belief in God and piety along with daily exercises such as contemplation in creation, contemplation in the horizons and soul, fasting, worship, reading the Qur'an and sincere contemplation in verses. Some abilities and characteristics, such as wisdom, creativity and compassion, which are developed with spiritual awakening, are the result of religion. In general, the principles introduced in basic religion, such as achieving unity beyond apparent plurality, finding answers about the origin of the universe and identifying spiritual patterns and regulating behaviour based on them, are the main axes of $\mathrm{SQ}$. With the growth of SQ, we can nurture religious people. The SQ teaches people compassion, kindness, unity in differences and reliance on meaning (Manjezi 2011).

\section{Methodology}

The statistical population of this study consisted of 5000 employees from 40 manufacturing and service organisations in Kuala Lumpur who were active in the field of education, insurance and food industry. In this study, simple random sampling method was selected for sampling. After distributing the questionnaire amongst the individuals, 4125 questionnaires were identified as appropriate and the rest were excluded from the analysis. Standard questionnaires were used to collect data and measure variables. The SQ was measured by a questionnaire proposed by Wolman (2001) and organisational citizenship behaviour was assessed by a questionnaire developed by Podsakoff et al. (1990). It is worth noting that the present study used a 5 -point Likert scale ranging from (1) strongly disagree to (5) strongly agree.
The validity of the questionnaires was determined using content validity and construct validity. In order to determine the content validity, research questionnaires were presented to 15 faculty members of the university who specialised in spirituality and Islamic principles. After reviewing their comments, the questionnaire questions were approved. In addition, Fitness Indices in Structural Equation Modeling in LISREL software was used to evaluate the construct validity. Root Mean Squared Error of Approximation (RMSEA) index less than 0.1, Chi-Square/df less than 3 and $p$-value less than 0.05 indicate acceptable construct validity. In addition, first 30 questionnaires were distributed amongst the statistical sample, and then their reliability was calculated through Cronbach's alpha test in SPSS software.

Cronbach's alpha coefficients above 0.7 confirm the reliability of the measurement tool and can be the basis for further research. The Kaiser-Meyer-Olkin (KMO) test was used to assess the adequacy of sampling. The test results indicated the appropriate statistical sample size for further research. In this study, the KMO statistic was 0.744 ; therefore, the sample size was suitable for research. The significance level (Sig) was also equal to 0.000 , which indicated the adequacy of sampling.

\section{Results}

In the present study, the one sample $t$-test was performed to assess the current status of each of the research variables in the study population. In this test, the sample mean was examined at the error level of 0.05 . In this test, utility is the mean higher than the contract value of 3 (mean value) in positive concepts and the mean less than the contract value of 3 in negative concepts, and SPSS16 software was used to perform the test. This test determines the status of each of the research variables. Table 2 shows the one sample $t$-test results.

In addition, Figure 1 and Table 3 show the test results of research hypotheses by structural equation modelling in LISREL 8.8 software. Figure 1 presents the Structural Equation

TABLE 1: Cronbach's alpha coefficient of the questionnaires.

\begin{tabular}{lcc}
\hline Variables/components & Number of questions & Cronbach's alpha \\
\hline Spiritual intelligence & 28 & 0.83 \\
Organisational citizenship behaviour & 24 & 0.81 \\
\hline Total & $\mathbf{5 2}$ & $\mathbf{0 . 9 0}$ \\
\hline
\end{tabular}

TABLE 2: One sample $t$-test results.

\begin{tabular}{lccccc}
\hline Variables & $\boldsymbol{N}$ & Mean & SD & $\boldsymbol{T}$ & Sig. \\
\hline Spiritual intelligence & 4125 & 3.7225 & 0.27232 & 41.784 & 0.000 \\
Organisational citizenship behaviour & 4125 & 4.2060 & 0.53371 & 35.440 & 0.000 \\
\hline
\end{tabular}



FIGURE 1: Structural equation modelling of research. 
TABLE 3: Test results of research hypotheses.

\begin{tabular}{llccl}
\hline Number & Hypothesis & $\boldsymbol{p}$ & $\boldsymbol{T}$-value & Result \\
\hline 1 & $\begin{array}{l}\text { Spiritual intelligence organisational } \\
\text { citizenship behaviour }\end{array}$ & 0.68 & 4.37 & $\begin{array}{l}\text { Significant \& } \\
\text { positive }\end{array}$ \\
\hline
\end{tabular}

Modelling and T-Value Model between the research variables. The standard coefficient of the existing relationship will be significant at the $95 \%$ confidence interval if the significant value is greater than 1.96 or less than -1.96 . Table 3 also presents the relationship between research variables in terms of research hypotheses, based on which the hypothesis has been confirmed or rejected.

\section{Discussion}

The present study aimed to investigate the role of SQ on the OCB of 5000 employees from 40 manufacturing and service organisations in Kuala Lumpur. After distributing the questionnaire amongst the individuals, 4125 questionnaires were identified as appropriate and the rest were excluded from the analysis. The results of the present study indicated a positive and significant relationship between SQ and OCB ( $p=$ $0.8 \& T$ Value $=4.37$ ). In addition, the results of the one sample $t$-test demonstrated the appropriate status of SQ (Mean = 3.725) and OCB (4.2060), confirming a positive relationship between the research variables. The results of this study that were in accordance with the researches confirm the positive relationships between spiritual intelligence and citizenship behaviours (e.g. Doostar, Chegini \& Pourabbasi 2012; Fattahi, Farhangi \& Vasegh 2006; Rastgar et al. 2012; Wills 2018).

Although limited research has been performed on the development of SQ and there is a need for qualitative and experimental research, it can be said that the talent of this intelligence, like other types of intelligence, is different in individuals and is gradually transformed and formed as a result of dealing with rich environments that raise spiritual questions. Researchers believe that conscious awareness and adaptation to life events and experiences and self-awareness are amongst the main factors in the development of SQ. The SQ is nurtured by increasing the breadth and openness of the mind, different points of view, high sensitivity to experiences and realities such as excellence. The SQ can be enhanced by various exercises, attention, change of emotions and strengthening of moral behaviours; however, those exercises are more about religion. The SQ grows by searching for the true meaning of situations, asking the why of different things and trying to make connections between events. In addition, the SQ is enhanced through learning, recognising and listening to intuitive instructional messages, thinking, raising self-awareness, learning from mistakes and self-honesty. As each of the different types of intelligence develops to different degrees, one of them may grow a lot in one person, whilst the other types have not grown much. Unresolved emotional or moral issues hinder spiritual growth. Spiritual maturity, as one of the manifestations of SQ, means a degree of emotional maturity and moral maturity (moral spirit) and moral behaviour and includes wisdom and compassion for others regardless of gender, ethnicity, age or race. Developed SQ is manifested through attributes such as originality, integrity, humility, kindness, generosity, patience, flexibility and selfsacrifice for others when needed. These traits represent the spiritual traits, which most followers of religions typically desire to practice in their daily lives. In general, it can be said that capabilities, capacities and behaviours such as regular internal and external thinking, self-assessment, nurturing a self-transcendent orientation, expanding interpersonal relationships, adhering to a range of spiritual and religious practices and constantly performing virtuous behaviours such as forgiveness and patience can be very helpful for the growth and development of SQ.

Religious beliefs and practices interpersonally enable the individuals to physiologically, cognitively and emotionally control their anger and help them take responsibility for their actions in conflicts. Interpersonally, religious practices provide the conditions for one to turn to God in anger and provide support for both couples to avoid conflict with each other. Communication with God has an interactive and compensatory role in relation to marital relationships. Spirituality is an organised system of beliefs embarrassing moral values, rituals and participation in a religious community for a stronger belief in God or a higher power. Religious beliefs are an effective way to deal with suffering and painful experiences. They also affect how human relationships work in times of trouble and distress. Faithful persons with spiritual connections and beliefs feel less abandoned, empty and lonely. The SQ provides human access to meaning and value, as well as their use in the way of thinking and deciding; therefore, people with high SQ seem to be less likely to have mental health problems. The concept of SQ refers to a type of adaptation and problemsolving behaviour, which includes the highest levels of development in various areas of cognitive, moral, emotional aspects and helps the individual to adapt to the surrounding phenomena and achieve internal, external and mental health. The SQ gives a person an overview of life and work environment and leads him or her to internal and external peace that plays a vital role in improving people's mental health, which is one of the important organisational consequences in the emergence of OCBs.

\section{Conclusion}

The OCB, as one of the new concepts of industrial psychology and organisational behaviour management emphasising the meta-role behaviours of employees and managers, plays a crucial role in the organisational process and transforms the traditional environment into a dynamic and efficient one. Therefore, if manufacturing and service organisations take decisive steps to establish $\mathrm{OCB}$, organisational efficiency and productivity will increase and this will improve their performance. In order to achieve this and strengthen the OCB of employees, the managers of the organisation, as the results of the present study showed, should be diligent in strengthening this goal. Amongst the influential components of OCB, this research focuses solely on SQ and combines the concepts of organisational behaviour with religious concepts. 
Therefore, future research is proposed to investigate other components related to OCB and apply the results in manufacturing and service organisations.

\section{Acknowledgements Competing interests}

The authors declare that they have no financial or personal relationships that may have inappropriately influenced them in writing this article.

\section{Authors' contributions}

All authors contributed equally to this work.

\section{Ethical considerations}

This article followed all ethical standards for research without direct contact with human or animal subjects.

\section{Funding information}

This research received no specific grant from any funding agency in the public, commercial or not-for-profit sectors.

\section{Data availability}

Data sharing is not applicable to this article as no new data were created or analysed in this study.

\section{Disclaimer}

The views and opinions expressed in this article are those of the authors and do not necessarily reflect the official policy or position of any affiliated agency of the authors.

\section{References}

Adams, K. \& Hyde, B., 2008, 'Children's grief dreams and the theory of spiritual intelligence', Dreaming 18, 58-67. https://doi.org/10.1037/1053-0797.18.1.58

Amrai, K., Farahani, A., Ebrahimi, M. \& Bagherian, V., 2011, 'Relationship between personality traits and spiritual intelligence among university students', Procedia Socia and Behavioral Sciences 15, 609-612. https://doi.org/10.1016/j.sbspro.2011.03.149

Bateman, T.S. \& Organ, D.W., 1983, 'Job satisfaction and the good soldier: The relationship between affect and employee citizenship', Academy of Management Journal 26(4), 587-595. https://doi.org/10.2307/255908

Bigdeloo, M. \& Bozorgi, Z.D., 2016, 'Relationship between the spiritual intelligence, self-control, and life satisfaction in High School Teachers of Mahshahr City', Review of European Studies 8(2), 210-216. https://doi.org/10.5539/res.v8n2p210

Bolino, M.C., Hsiung, H.-H., Harvey, J. \& LePine, J.A., 2015, “'Well, I'm tired of tryin'!" Organizational citizenship behavior and citizenship fatigue', Journal of Applied Psychology 100(1), 56-74. https://doi.org/10.1037/a0037583

Chan, S.H.J. \& Lai, H.Y.I., 2017, 'Understanding the link between communication satisfaction, perceived justice and organizational citizenship behavior', Journal of Business Research 70(1), 214-223. https://doi.org/10.1016/j.jbusres.2016.08.017

Cropanzano, R., Rupp, D.E. \& Byrne, Z.S., 2003, 'The relationship of emotional exhaustion to work attitudes, job performance, and organizational citizenship behaviors', Journal of Applied Psychology 88(1), 160-169. https://doi.org/ 10.1037/0021-9010.88.1.160

Doostar M., Chegini, M.G. \& Pourabbasi, S., 2012, 'Survey of relationship between spiritual intelligence and organizational citizenship behavior', Interdisciplinary Journal of Contemporary Research in Business 11(3), 54-61.
Du, S.A., Mazdarani, S. \& Ghasemian, D., 2013, 'The relationship between spiritual intelligence and stress among teachers', Journal of Social Issues \& Humanities 1(6), 58-60.

Emmons, R.A., 2000a, 'Is spirituality an intelligence? Motivation, cognition, and the psychology of ultimate concern', The International Journal for the Psychology of Religion 10(1), 3-26. https://doi.org/10.1207/S15327582IJPR1001_2

Emmons, R.A., 2000b, 'Spirituality and intelligence: Problems and prospects', International Journal for the Psychology of Religion 10(1), 57-64. https://doi. org/10.1207/S15327582IJPR1001_6

Fattahi, M., Farhangi, A.A. \& Vasegh, B., 2006, 'Spirituality in the workplace and its role in improving citizenship behavior in the organization, management culture', Issue 13, 36-35.

Fry, L.W., 2003, 'Toward a theory of spiritual leadership', The Leadership Quarterly 14(6), 693-727. https://doi.org/10.1016/j.leaqua.2003.09.001

Ghobari Bonab, B., Gholam Ali Lavasani, M. \& Mohammadi, M.R., 2005, 'Construction of a scale for students' spiritual experiences', Journal of Psychology 35(1), 272-278.

Gieseke, A.R., 2014, 'The relationship between spiritual intelligence, mindfulness, and transformational leadership among public higher education leaders', unpublished dissertation, College of Professional Studies, Northeastern University, Boston, MA.

Griffiths, R.R., Richards, W.A., Johnson, M.W., McCann, U.D. \& Jesse, R., 2008, 'Mystical-type experiences occasioned by psilocybin mediate the attribution of personal meaning and spiritual significance 14 months later', Journal of Psychopharmacology 22(6), 621-632. https://doi.org/10.1177/02698811080 94300

Khaninzadeh, M., 2016, 'Spiritual intelligence in the teachings of Islam', Masters' thesis in Quran and Hadith, Payame Noor University.

King, D.B. \& DeCicco, T.L., 2009, 'A viable model and self-report measure of spiritual intelligence', International Journal of Transpersonal Studies 28(1), 68-85. https:// doi.org/10.24972/ijts.2010.28.1.68

Koys D.J., 2001, 'The effects of employee satisfaction, organizational citizenship behavior, and turnover on organizational effectiveness: A unit-level, longitudinal study', Personnel Psychology 54(1), 101-114. https://doi.org/10.1111/j.17446570.2001.tb00087.x

Levin, S.M., 2000, 'Put the shoulder to the wheel: A new biomechanical model for the shoulder girdle', in C. Ribreau (ed.), Mechano transduction, pp. 131-136, Societe biomechanique, Paris.

Manjezi, F., 2011, 'Study of the effect of Islamic communication and religious attitudes on improving marital satisfaction', Behavioral Sciences Research 10(1), 30-37.

Nasel, D.D., 2004, 'Spiritual orientation in relation to spiritual intelligence: A consideration of traditional Christianity and new age/individualistic spirituality', Unpublished Doctoral dissertation, University of South Australia.

Organ, D.W., 1988, Organizational citizenship behavior-the good soldier syndrome, 1st edn., D.C. Heath and Co., Lexington, MA.

Ozsahin, M. \& Sudak M.K., 2015, 'The mediating role of leadership styles on the organizational citizenship behavior and innovativeness relationship', Journa of Business, Economics \& Finance 4(4), 443-453. https://doi.org/10.17261/ Pressacademia.2015313065

Podsakoff, P.M. \& MacKenzie, S.B., 1994, 'Organizational citizenship behaviors and sales unit effectiveness', Journal of Marketing Research 31(3), 351-363. https:// doi.org/10.1177/002224379403100303

Podsakoff, P.M., MacKenzie, S.B., Moorman, R.H. \& Fetter, R., 1990, 'Transformational leader behaviors and their effects on followers' trust in leader, satisfaction, and organizational citizenship behaviors', Leadership Quarterly 1(2), 107-142. https:// doi.org/10.1016/1048-9843(90)90009-7

Rastgar, A., Zarei, A., Davoudi, S.M. \& Farlash, K., 2012, 'The link between workplace spirituality, organizational citizenship behavior and job performance in Iran', $A$ Journal of Economics and Management 1(6), 51-67.

Saidy, E.P., Hassan, A., Abd Rahman, F., Ab Jalil, H., Ismail, A.I. \& Krauss, E.S., 2009, 'Influence of emotional and spiritual intelligence from the national education philosophy towards language skills among secondary school students', European Journal of Social Sciences 9(1), 61-71.

Tischler, L., Biberman, J. \& McKeage, R., 2002, 'Linking emotional intelligence, spirituality and workplace performance', Journal of Managerial Psychology 17(3), 203-218. https://doi.org/10.1108/02683940210423114

Vaughan, F., 2002, 'What is spiritual intelligence?', Journal of Humanistic Psychology 42(2), 16-33. https://doi.org/10.1177/0022167802422003

Wills, A., 2018, 'Emotional and spiritual intelligence in the workplace in relation to organizational citizenship behavior', Doctoral dissertation, Kaplan University.

Wolman, R.N., 2001, Thinking with your Soul: Spiritual Intelligence and why it Matters, Harmony Books, New York, NY.

Yang, K., 2006, 'The spiritual intelligence of nurses in Taiwan', Journal of Nursing Research 14(1), 24-35. https://doi.org/10.1097/01.JNR.0000387559.26694.0b

Zohar, D. \& Marshall, I., 2000, SQ: Spiritual intelligence, the ultimate intelligence, Bloombury, New York, NY. 